\title{
Brightening of onset arc precedes the dipolarization onset: THEMIS observations of two events on 1 March 2008
}

\author{
J. R. Kan ${ }^{1,2}$, H. Li ${ }^{1}$, C. Wang ${ }^{1}$, H. U. Frey ${ }^{3}$, M. V. Kubyshkina ${ }^{4}$, A. Runov ${ }^{5}$, C. J. Xiao ${ }^{6}$, L. H. Lyu ${ }^{7}$, and W. Sun ${ }^{2}$ \\ ${ }^{1}$ National Space Science Center, CAS, Beijing, China \\ ${ }^{2}$ Geophysical Institute, University of Alaska Fairbanks, AK, USA \\ ${ }^{3}$ Space Sciences Laboratory, UC Berkeley, CA, USA \\ ${ }^{4}$ St. Petersburg State University, St. Petersburg, Russia \\ ${ }^{5}$ Institute of Geophysics and Planetary Physics, UCLA, CA, USA \\ ${ }^{6}$ School of Physics, Peking University, Beijing, China \\ ${ }^{7}$ Institute of Space Science, National Central University, Chung-Li, Taiwan
}

Received: 5 July 2011 - Revised: 2 October 2011 - Accepted: 27 October 2011 - Published: 17 November 2011

\begin{abstract}
We present a new M-I coupling model of substorm during southward IMF based on the THEMIS observations of two events on 1 March 2008. The first event (E-1) was classified as a pseudo-breakup: brightening of the onset arc preceded the first dipolarization onset by $\sim 71 \pm 3 \mathrm{~s}$, but the breakup arcs faded within $\sim 5$ min without substantial poleward expansion and the dipolarization stopped and reversed to thinning. The second event (E-2) was identified as a substorm: brightening of the second onset arc preceded the second dipolarization onset by $\sim 80 \pm 3 \mathrm{~s}$, leading to a full-scale expanding auroral bulge during the substorm expansion phase for $\sim 20 \mathrm{~min}$. The Alfvén travel time from the ionosphere to the dipolarization onset region is estimated at $\sim 69.3 \mathrm{~s}$ in E-1; at $\sim 80.3 \mathrm{~s}$ in E-2, which matched well with the observed time delay of the dipolarization onset after the brightening of the onset arc, respectively in E-1 and E-2. Brightening of the onset arc precedes the dipolarization onset suggest that the onset arc brightening is caused by the intense upward field-aligned currents originating from the divergence of the Cowling electrojet in the ionosphere. The Cowling electrojet current loop (CECL) is formed to close the field-aligned currents at all times. The closure current in the Alfvén wavefront is anti-parallel to the cross-tail current. Dipolarization onset occurs when the Alfvén wavefront incident on the near-Earth plasma sheet to disrupt the crosstail current in the dipolarization region. Slow MHD waves dominate the disruption of the cross-tail current in the dipolarization region.
\end{abstract}

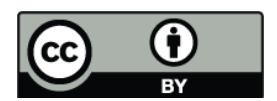

Correspondence to: $\mathrm{H} . \mathrm{Li}$ (hli@spaceweather.ac.cn)
Keywords. Magnetospheric physics (Magnetosphereionosphere interactions)

\section{Introduction}

Akasofu (1964) proposed the first morphological model of auroral substorm, which captured the essence of the substorm phenomenon. The auroral dynamics observed in the ionosphere by Akasofu (1964) and the plasma dynamics observed in the plasma sheet by Hones Jr. et al. (1984) suggested that the substorm phenomenon involves the magnetosphere-ionosphere (M-I) coupling processes modeled by Wolf (1970), Coroniti and Kennel (1973), Bostrom (1974), Maltsev et al. (1974), Goertz and Boswell (1979), Pashin et al. (1982), Senior and Blanc (1984), Kaufmann (1987), Kan and Sun (1996).

Mozer (1971) showed, balloon-measured average ionospheric E-field in the midnight sector between $L=6.6$ and 8.3 , that the ratio of southward to westward E-field components is $\sim 1.5$ during substorms. The significance of Mozer's (1971) results is that the westward auroral electrojet is intensified to become the westward Cowling electrojet by the southward E-field driving the westward Hall current superposed on the westeard Pedersen current during substorms. Hereafter the westward Cowling current will be called the Cowling electrojet. During substorms, the auroral electrojet is intensified to become the Cowling electrojet. Divergence (convergence) on the dusk (dawn) side of the Cowling electrojet channel leads to formation of the CECL (Cowling electrojet current loop). The field-aligned currents in the CECL are closed in the Alfvén wavefront, which leads the

Published by Copernicus Publications on behalf of the European Geosciences Union. 
propagation of CECL towards the plasma sheet, as proposed in the present paper.

Heppner and Maynard (1987) showed the southward E-field as a characteristic distortion of the two-cell convection pattern during disturbed periods. Kamide and Kokubun (1996) showed that the presence of the southward E-field in the midnight sector is essential during substorms, which is confirmed by the M-I coupling model calculation (Kan and Sun, 1996) that the Cowling electrojet intensifies drastically by adding an assumed southward E-field in the midnight sector.

The dipolarization onset in the new M-I coupling substorm model is driven by the interaction between the CECL (Cowling electrojet current loop) and the near-Earth plasma sheet. The interaction excites the slow MHD waves to disrupt the cross-tail current in the dipolarization region, leading to the substorm expansion phase. The new dipolarization onset mechanism is fundamentally different from the two highly popular dipolarization models: The NENL model (Baker et al., 1996; Anglopoulos et al., 2008) attributes the dipolarization onset to the braking of earthward plasma flows (Shiokawa et al., 1997; Dubyagin et al., 2010). The inverse cascade model (Lui et al., 2008) ascribes the dipolarization onset to the inverse cascade of cross-tail current instability, which was deemed doubtful by Vörös et al. (2010).

\subsection{What produces the southward electric field observed in the midnight sector?}

Mozer (1971) observed the southward electric field in the midnight sector during substorms. Kan (2007) derived the southward E-field in the midnight sector ( 20:00 to $\sim 02: 00$ MLT), based on the blockage of the northward Hall currents from closure in the equatorial plane. The blockage of the northward Hall currents from closure is a direct consequence of the absence of radial currents in the equatorial plane in the midnight sector as observed by Iijima et al. (1990).

The ratio of westward Cowling current to the westward Pedersen current in the midnight sector derived by Kan (2007) is given by

$$
I_{\mathrm{C}} / I_{\mathrm{P}}=\left[1+\alpha\left(\Sigma_{\mathrm{H}} / \Sigma_{\mathrm{P}}\right)^{2}\right]
$$

The ratio of southward to westward E-field components is given by

$$
E_{\mathrm{S}} / E_{\mathrm{W}} \approx \alpha\left(\Sigma_{\mathrm{H}} / \Sigma_{\mathrm{P}}\right)
$$

where $\alpha$ is the blockage parameter ranging between $0 \leq \alpha \leq$ 1 with $\alpha=0$ for zero blockage and $\alpha=1$ for complete blockage. Assuming $\Sigma_{\mathrm{H}} / \Sigma_{\mathrm{P}} \sim 2$ and $\alpha \sim 0.75$, one obtains the current ratio $I_{\mathrm{C}} / I_{\mathrm{P}} \sim 4$ from Eq. (1) and the E-field ratio $E_{\mathrm{S}} / E_{\mathrm{W}} \sim 1.5$ from Eq. (2). The Cowling to Pedersen elecrojet intensity ratio depends on the blockage parameter $\alpha$ and the Hall to Pedersen conductance ratio as shown in Eq. (1).
It should be emphasized that enhancement of the Cowling electrojet current by a factor of 4 without increasing the westward convection E-field. In other words, Cowling electrojet is enhanced without enhancing the earthward convection driven by reconnection in the near-Earth plasma sheet.

\subsection{Oval conductance produced by precipitations from the plasma sheet}

Oval conductance is an intrinsic non-uniform conductance of the ionosphere produced by particles precipitating from the plasma sheet. The oval conductance is related to the plasma pressure distribution in the plasma sheet. The oval conductance exist even during quiet times at $\mathrm{Kp}=0$. Oval conductance intensified during magnetic storms as Kp index increases toward its peak value of 9 .

Hardy et al. (1987) show that the oval conductance is distributed around the auroral oval, peaks in the midnight sector decreasing towards the dayside. The belt-shaped oval conductance centers around $\sim 67^{\circ}$ latitude for low $\mathrm{Kp}$ index and shifted to lower latitudes around $\sim 62^{\circ}$ for higher $\mathrm{Kp}$ values.

The oval conductance is inherently non-uniform. Its azimuthal and latitudinal gradients in the midnight sector are essential to the field-aligned currents flowing to-and-from the auroral electrojet in the ionosphere. The non-uniform oval conductance is crucial to the transition of the M-I coupling from a quiet state to a disturbed state.

\section{Nomenclature of acronyms used in the present paper}

AM02 magnetic field model (Kubyshkina et al., 2009) is based on the T96 model (Tsyganenko, 1995) with only one modification in that the neutral sheet position is not fixed; it may be rotated by a small angle ( \pm 6 degrees) in the X-Z plane in the GSM coordinates. The angle of rotation is considered to be a free parameter of the model together with the input parameters of the T96 model, i.e., the solar wind dynamic pressure, the IMF (interplanetary magnetic field) $\boldsymbol{B}_{Y}$ and $\boldsymbol{B}_{Z}$ components and the Dst index. In the standard T96 model these parameters are taken from the solar wind and ground data; in the adaptive AM02 model they are treated as free parameters obtained by minimizing the square deviations between the model and observations. The error function, which was minimized for this substorm event included the field components square deviations at all 5 THEMIS (TH) satellites together with the lobe field square deviations at TH$\mathrm{B}$ and TH-C. The observed lobe field was calculated from plasma pressure and observed magnetic field. The modeled lobe field was calculated as the total magnetic field in the lobe above the spacecraft position. Only distant TH-B and TH-C probes were taken to control the model lobe field (or pressure balance across the neutral sheet) to avoid possible difficulties with non-planar field configuration at smaller distances. The model is constructed with 5 min resolution (the 


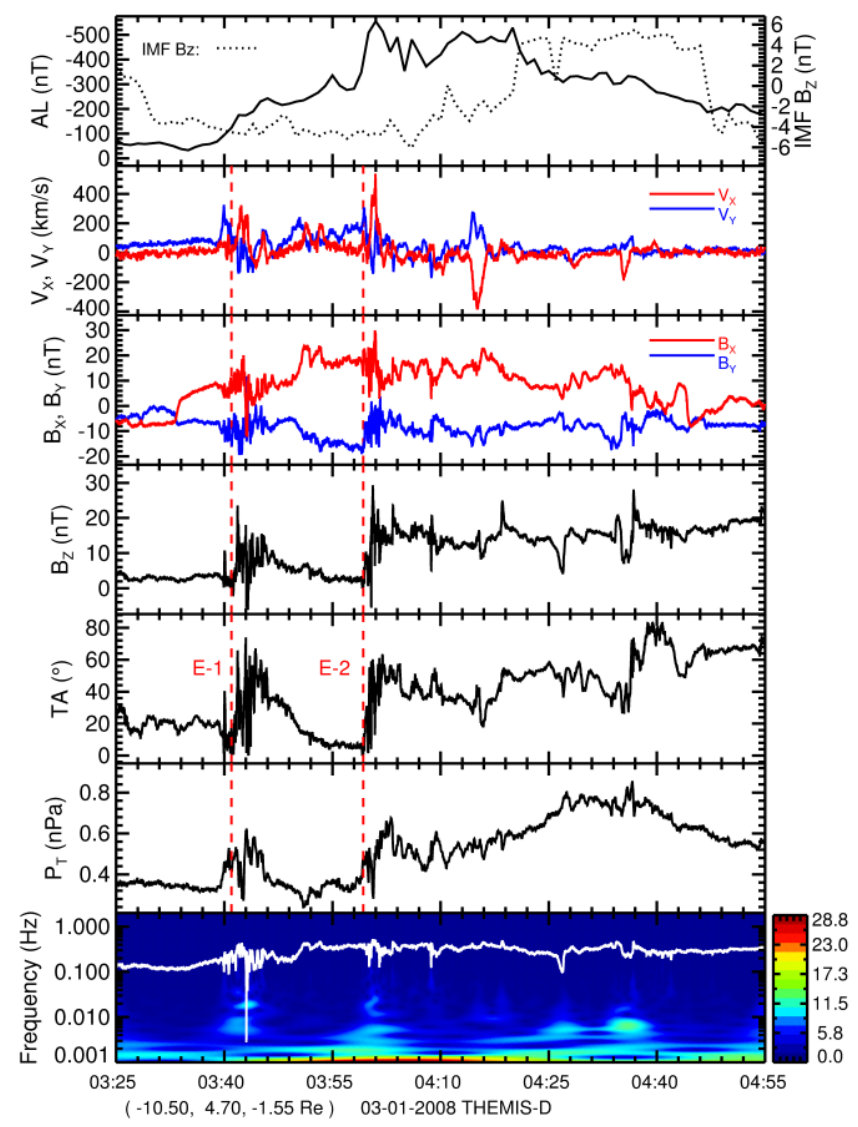

Fig. 1a. Summary plot of TH-D observations at $(-10.50,4.70$, $-1.55 R e$ ), Kyoto-AL index from (of 1-min resolution) and OMNIIMF $\boldsymbol{B}_{Z}$ in GSM coordinates shifted to the nose of bow shock. The TH-D data include the flow speeds $V_{X}$ in red and $V_{Y}$ in blue (of 3-s resolution), the magnetic field components $\boldsymbol{B}_{X}$ and $\boldsymbol{B}_{Z}$ (of 0.25 -s resolution) in the plasma sheet, the magnetic tilt angle TA from the equatorial plane, the thermal pressure $P_{\mathrm{T}}$, and the Morlet wavelet spectrum.

free parameters of the model are calculated for each 5 min of data and thus is based on the 5-min averaged data sets). Appendix A shows that the AM02 reproduces the observed THEMIS B-field much better than that of the T96.

ASI's are the THEMIS All-Sky Images of 3-s resolution, designed to study the auroral dynamics during substorms (Mende et al., 2008).

Brightening of the onset arc refers to brightening of auroral arc leading to dipolarization onset, which in turn may lead to a substorm or a pseudo-breakup. Brightening of onset arc is determined by the integrated image total (IT) brightness in the midnight sector ranging from $\sim 20: 00$ MLT to $\sim 02$ :00 MLT.

CECL stands for the Cowling electrojet current loop, which is formed by the divergence (convergence) on the dusk (dawn) side of the Cowling electrojet channel. The fieldaligned currents in the CECL are closed in the Alfvén wave-

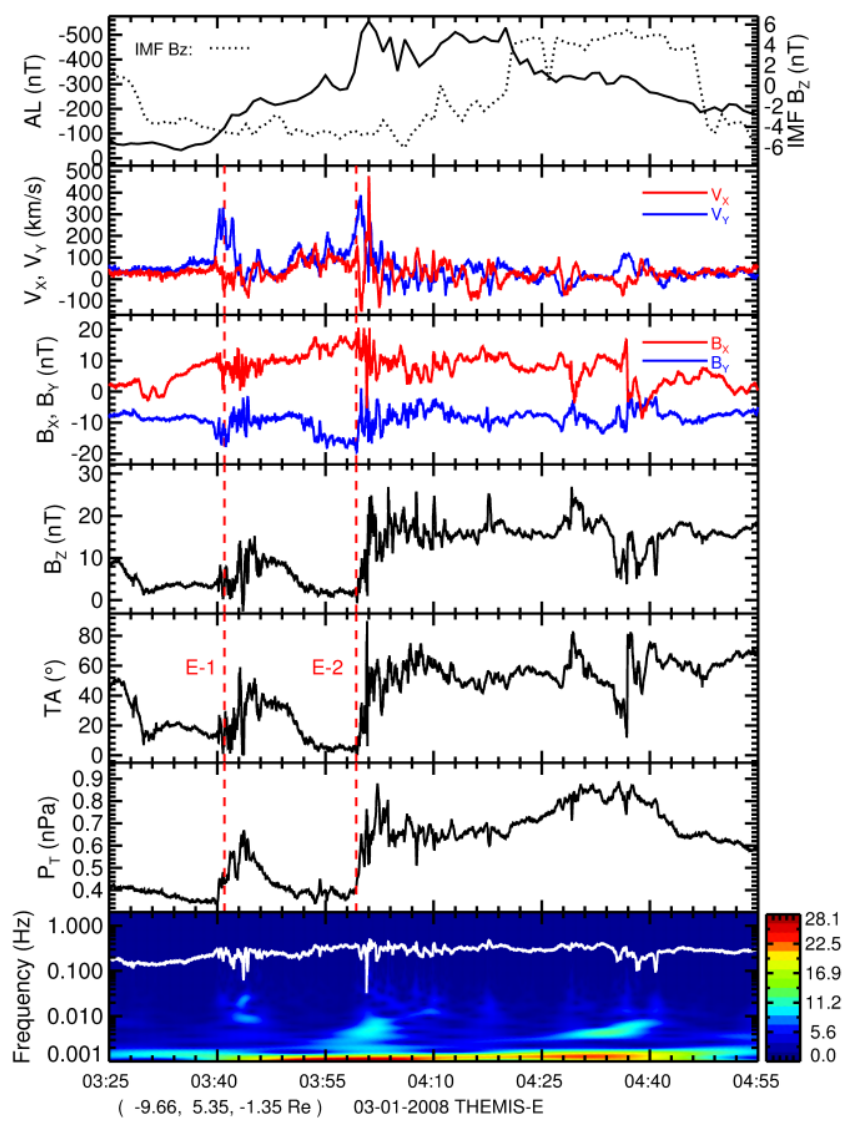

Fig. 1b. Summary plot of TH-E observations at (-9.66, 5.35, $-1.35 R e$ ) in the same format as in (a). Comparisons between $\mathrm{TH}-$ $\mathrm{D}$ and TH-E data are discussed in Sect. 4.

front, which leads the propagation of the CECL towards the plasma sheet.

$G M L$ denotes geomagnetic latitude.

$G S M$ is the geocentric solar-magnetosphere coordinates in which the $\mathrm{X}$-axis is pointing from the Earth to the Sun, the $Y$-axis is normal to the plane of the Earth's magnetic dipole cross into the $\mathrm{X}$-axis, and the $\mathrm{Z}$-axis is normal to the $\mathrm{X}-\mathrm{Y}$ plane.

IT stands for the image total brightness obtained by integrating the digital brightness of the all-sky image of 3-s resolution. The IT plot versus time is a digital representation of the auroral image array.

$T A$ denotes magnetic field "Tilt Angle" from the equatorial plane in the plasma sheet, defined by $\mathrm{TA}=$ arc-tan $\left[\boldsymbol{B}_{Z} /\left(\boldsymbol{B}_{X}^{2}+\boldsymbol{B}_{Y}^{2}\right)^{1 / 2}\right]$ in degrees, in the GSM coordinates. TA increases as the dipolarization intensifies.

\section{THEMIS observations of two events on 1 March 2008}

Figure 1a is a summary plot of the two events observed by TH-D at $(-10.50,4.70,-1.55 R e)$ on 1 March 2008 from $\sim 03: 25$ to $\sim 04: 55$, including the period of southward IMF: 
the IMF $\boldsymbol{B}_{Z}$ in the top panel (of 1-min resolution shifted to the bow shock nose) is obtained from the OMNI data set as shown in the dotted curve on the right-hand scale. IMF turned southward at $\sim 03: 28 \mathrm{UT}$, with $\boldsymbol{B}_{Z} \sim-4$ to $-6 \mathrm{nT}$, until it turned northward at $\sim 04: 20$ UT.

The AL index in the top panel (of 1-min resolution) obtained from the Kyoto WDC is a measure of the westward electrojet current intensity, as shown in the solid curve on the left-hand scale. The Kyoto-AL index decreases from $\sim-50 \mathrm{nT}$ to $\sim-250 \mathrm{nT}$ during the first event (E-1); it decreases further from $\sim-250 \mathrm{nT}$ to $\sim-550 \mathrm{nT}$ during the second event (E-2). Each dipolarization onset is accompanied by an observed decrease in the Kyoto-AL index. Comparison of the Kyoto-AL index and the TH-AL index will be discussed later in Fig. 3.

The panel on $V_{X}$ (in red) and $V_{Y}$ (in blue) shows the plasma flow speeds observed at TH-D in the GSM coordinates, which include the BBF-like flow bursts with $\left|V_{X}\right|>$ $100 \mathrm{~s} \mathrm{~km} \mathrm{~s}^{-1}$ localized in $|Y|<$ a few $R_{\mathrm{E}}$ (Baumjohann et al., 1990; Angelopoulos et al., 1992; Nakamura et al., 2004), and the global-scale low-speed convection of a few $\sim 10 \mathrm{~s} \mathrm{~km} \mathrm{~s}^{-1}$. The flow speeds are obtained from the combined ESA and SST energy channels observed at TH-D. We note that a BBF-like flow burst with $V_{X} \sim 300 \mathrm{~km} \mathrm{~s}^{-1}$ is observed to follow closely the dipolarization onset in E-1; a BBF with $V_{X} \sim 600 \mathrm{~km} \mathrm{~s}^{-1}$ is observed to follow the dipolarization onset in E-2, as shown in Fig. 1a. The cause-and-effect relationship between the BBF and the dipolarization onset need to be assessed by a comprehensive statistical study, which is beyond the scope of the case study of this paper.

The panel on $\boldsymbol{B}_{X}$ and $\boldsymbol{B}_{Z}$ (of $0.25 \mathrm{~s}$ resolution) shows the magnetic field components in the GSM coordinates observed at TH-D located at $(-10.50,4.70,-1.55) R_{\mathrm{E}}$ at $\sim 04: 00 \mathrm{UT}$. Dipolarization onset is determined by the tilt angle (TA), defined in Sect. 2, as shown in Fig. 1a. Dipolarization onset of the first event (E-1) based on TA occurs at 03:41 UT. Dipolarization onset of the second event (E-2) exhibits a step-like increase in TA at $\sim 03: 59$ UT. Thinning of the plasma sheet is observed as TA decreases down to $\leq \sim 10^{\circ}$ within $\sim 3$ to $4 \mathrm{~min}$ prior to the dipolarization onset. Thinning prior to the dipolarization onset might be related to the explosive thinning observed by Ohtani et al. (1992).

Dipolarization onset of the pseudo breakup event in E-1 is accompanied by flucturations as shown in the TA plot, while the dipolarization onset of the substorm event in E-2 is free from such fluctuations. These features are observed in Fig. 1a as well as in Fig. 1b. Could the fluctuations observed in the dipolarization onset of pseudo breakups be a characteristic feature of pseudo breakups?

We note that a BBF (bursty bulk flow) with $V_{X} \sim$ $300 \mathrm{~km} \mathrm{~s}^{-1}$ is observed to follow closely the dipolarization onset in E-1; a BBF with $V_{X} \sim 600 \mathrm{~km} \mathrm{~s}^{-1}$ is observed to follow the dipolarization onset in E-2, as shown in Fig. 1a.

The thermal pressure $P_{\mathrm{T}}$ in Fig. 1a is obtained by combining the ESA and SST data in the plasma sheet: $P_{\mathrm{T}}=P_{i}$
$(\mathrm{ESA})+P_{i}(\mathrm{SST})+P_{e}(\mathrm{ESA})+P_{e}(\mathrm{SST})$ based on the procedure developed by Xing et al. (2010). The energy range for $\mathrm{ESA}$ is from a few $\mathrm{eV}$ to $25 \mathrm{keV}$ for ions and from a few $\mathrm{eV}$ to $30 \mathrm{keV}$ for electrons. The energy range for SST is from $25 \mathrm{keV}$ to $6 \mathrm{MeV}$ for ions and from $25 \mathrm{keV}$ to $1 \mathrm{MeV}$ for electrons. The result on $P_{\mathrm{T}}$ in Fig. 1a is not an official THEMIS team result. The plasma thermal pressure increases from $\sim 0.4 \mathrm{nPa}$ to $\sim 0.8 \mathrm{nPa}$ in the dipolarization region which is consistent with the increase of $\boldsymbol{B}_{Z}$ during the substorm expansion phase from $\sim 04: 00$ UT to $\sim 04: 20$ UT.

The bottom panel of Fig. 1a is the Morlet wavelet spectrum based on the method of Torrence and Compo (1998). The white curve across the top of the wavelet spectrum is the ion cyclotron frequency fluctuating around $\sim 0.1 \mathrm{~Hz}$ in the dipolarization region. The intense waves observed in the dipolarization region are predominantly MHD waves in the frequency range $\leq \sim 0.01 \mathrm{~Hz}$, much below the ion cyclotron frequency of $\sim 0.1 \mathrm{~Hz}$. The absence of waves near the ion cyclotron frequency in the wavelet spectrum is consistent with Vörös et al.'s (2010) conclusion that it is doubtful that the dipolarization in the plasma sheet was associated with the inverse cascade of energy transport from high frequency waves to low frequency waves.

Figure $1 \mathrm{~b}$ shows the TH-E observations of the two events in the same format as in Fig. 1a. The location of TH-E at $(-9.66,5.35,-1.35) R_{\mathrm{E}}$ at $\sim 04: 00 \mathrm{UT}$ is in close proximity to TH-D at $(-10.50,4.70,-1.55) R_{\mathrm{E}}$ at $\sim 04: 00 \mathrm{UT}$. Differences in the observed features between TH-D and TH-E are discussed below:

Comparing Fig. 1a and b, BBF $V_{X}$ is observed in E-1 at TH-D, but not observed in E-1 at TH-E, which may have been deflected duskward as seen in the large $V_{Y}>0$ in E-1 at TH-E. Indeed, TH-E was situated slightly duskward of TH$\mathrm{D}$, which also detected strong duskward flow ahead of the earthward flow. On the other hand, the observed behaviors of $V_{X}$ and $V_{Y}$ in E-2 at both TH-D and TH-E suggest that we could be sampling a vortex-like motion associated with the BBF observed in E-2.

Before the dipolarization onset in E-2 at $\sim 03: 59$ UT, TH-E $(Z=-1.35 R e)$ is above TH-D $(Z=-1.55 R e)$, and TH-D is above neutral sheet, since $\boldsymbol{B}_{X}$ is positive. Therefore, TH-D is closer to the neutral sheet than TH-E.

Following the dipolarization onset around $\sim 03: 59$ UT, the thermal pressure $P_{\mathrm{T}}$ at TH-E is observed to increase more than at TH-D. This is consistent with the TH-E being closer to the Earth than TH-D in $X$ by $\sim 0.84 R_{\mathrm{E}}$.

\subsection{Characteristics of the observed onset arcs}

Figure $2 \mathrm{a}$ shows the auroral activities observed during the first event (E-1) based on the TH-ASI at SNKQ of 1-min resolution. The MLT of SNKQ at 03:38 is $\sim 22: 26$ MLT. Although the brightening of the onset arc at $\sim 03: 42$ is quite intense, we would classify the first event (E-1) as a pseudobreakup for reasons given below: 


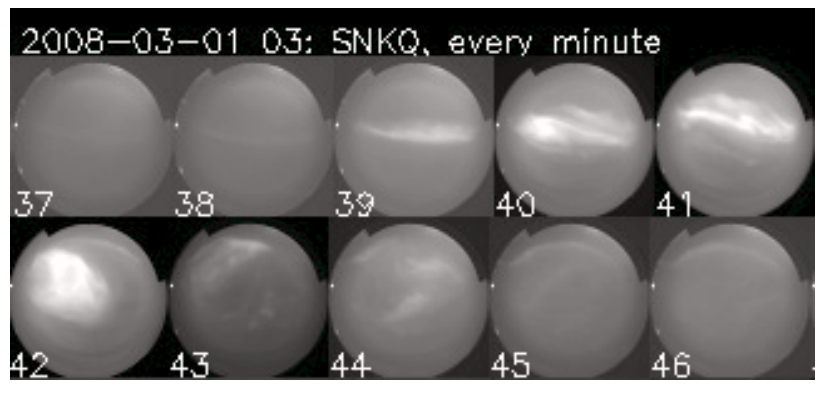

Fig. 2a. (a) shows ASI arrays of 1-min resolution at SNKQ during the first event E-1: brightening of onset arc occurs between $\sim 03: 39$ and $\sim 03: 40$. Brightness peaks and breaks up at $\sim 03: 42$, and faded within $\sim 5$ min without substantial poleward expansion. The first event is classified as a pseudo breakup.

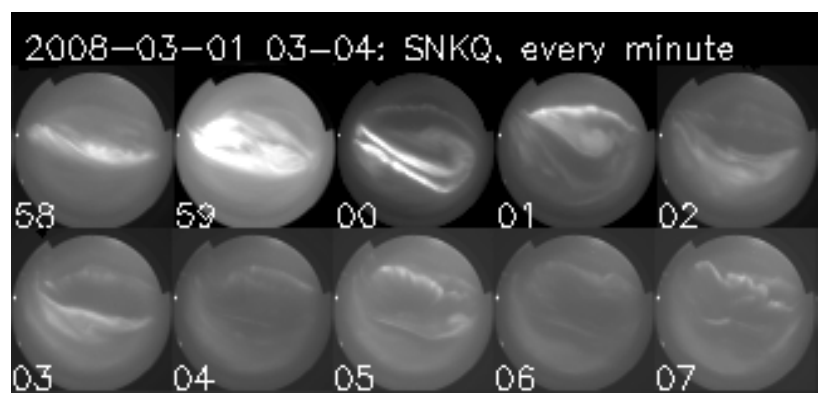

Fig. 2b. (b) shows ASI arrays of 1-minute resolution at SNKQ during the second event E-2: brightening of onset arc occurs between $\sim 03: 57$ and $\sim 03: 58$. Brightness peaks and breaks up at $\sim 03: 59$ and last at least for $9 \mathrm{~min}$ during the expansion phase. The second event is identified as a substorm.

- The breakup arcs fade within $\sim 3-4$ min, without substantial poleward expansion, as shown in Fig. 2a.

- Dipolarization measured by the magnetic field tilt angle TA halted within $\sim 5 \mathrm{~min}$ and reversed to thinning, as shown by the TA decreasing in Fig. 1a-b.

- Thermal pressure measured by $P_{\mathrm{T}}$ in the dipolarization region decreases within $\sim 5$ min, as shown in Fig. 1a-b.

Figure $2 \mathrm{~b}$ shows the auroral activities in the second event (E2) based on the TH-ASI array of 1-min resolution. Brightening of onset arc occurs between $\sim 03: 57$ and $\sim 03: 58$; the brightness peaks and breaks up to form the expanding auroral bulge during $\sim 03: 59$ to $\sim 04: 08$ of the expansion phase. Based on the auroral activity observed in Fig. $2 b$ and the dipolarization activity observed in Fig. 1a and b, we identify the second event (E-2) as a substorm.

The blockage parameter for the substorm event in E-2 shown in Fig. 1 can be crudely estimated based on Eq. (1) under the assumptions that the earthward convection has been enhanced during the growth phase and stays constant and the Hall-to-Pedersen conductance ratio is assumed constant at

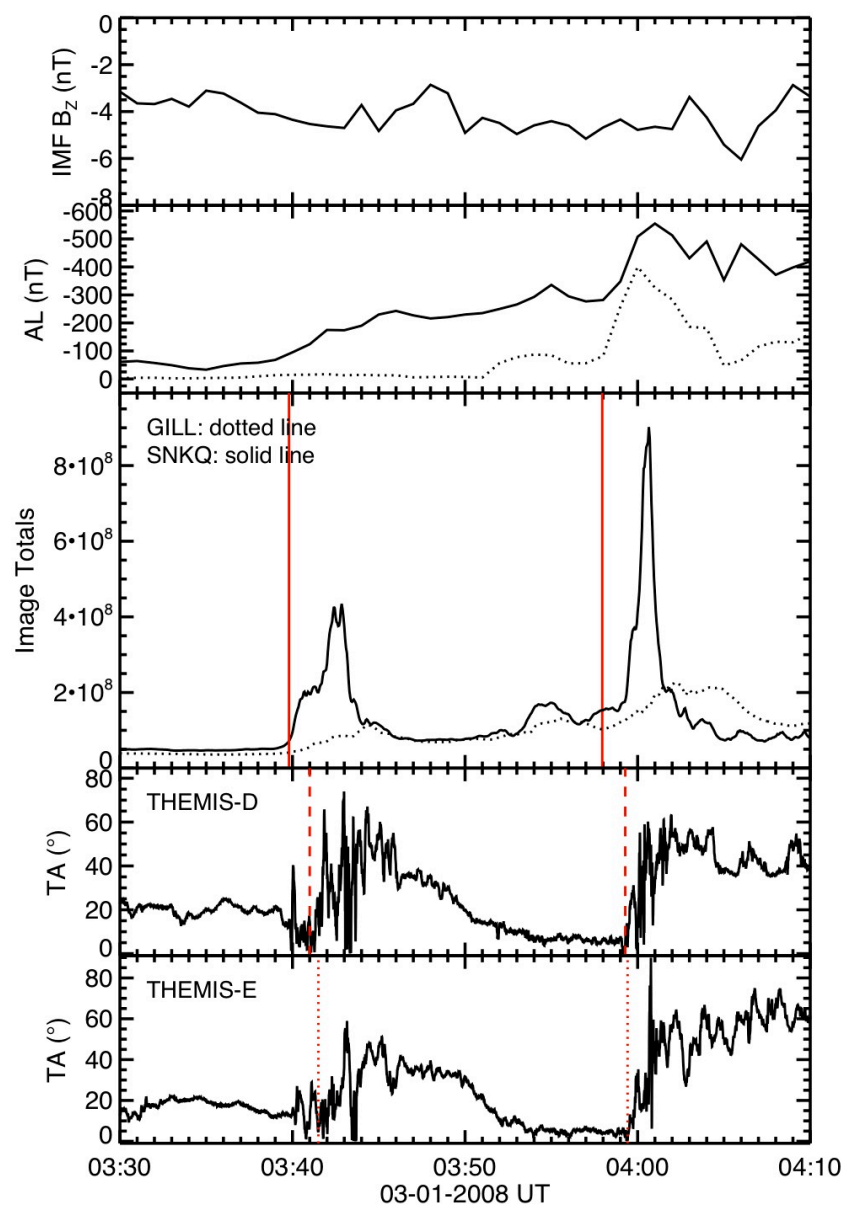

Fig. 3. Timing of key parameters during the two events: E-1 and E2. The IMF turned southward at $\sim 03: 28$ UT. The Kyoto-AL index in solid curve is of 1-min resolution. The TH-AL index in dotted curve is of 3-s resolution. The image total plots at GILL (dotted curve) and SNKQ (solid curve) are the digital display of the ASI arrays of 3-s resolution (not shown). The timing of onset arc can be determined from the image total line plots to within the uncertainty of $\pm 3 \mathrm{~s}$, limited by the ASI resolution.

$\Sigma_{\mathrm{H}} / \Sigma_{\mathrm{P}}=2$. The observed AL index is seen to increase by a factor of $\sim 5$ from $\sim 100 \mathrm{nT}$ to $\sim 500 \mathrm{nT}$ in the top panel of Fig. 1. The blockage parameter is estimated at $\alpha \sim 1$, according to Eq. (1).

\subsection{Timing between brightening of the onset arc and the dipolarization onset}

Figure 3 shows timing of key parameters during events E- 1 and E-2 under southward IMF $\boldsymbol{B}_{Z}$ : the Kyoto-AL index in solid curve (of 1-min resolution) shows two enhancements of the westward electrojet current: the first AL enhancement starts around $\sim 03: 39$ UT is associated with the brightening of onset arc in the first event E-1. The second AL enhancement occurs around $\sim 03: 57$ UT is associated with the brightening of onset arc in the second event E-2. The 
(A) at 03:48:00 UT

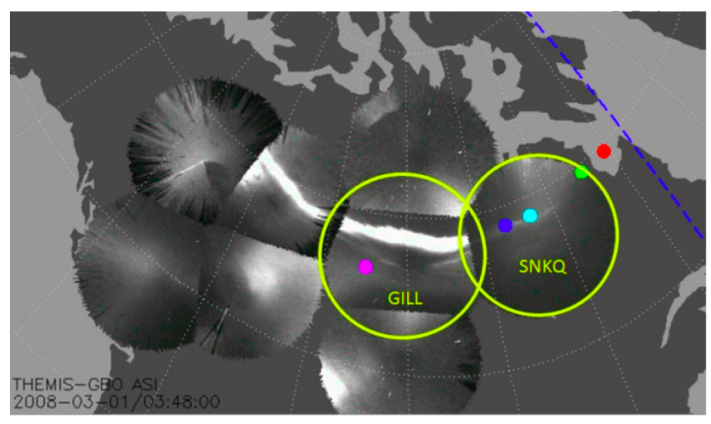

(C) at 04:03:00 UT

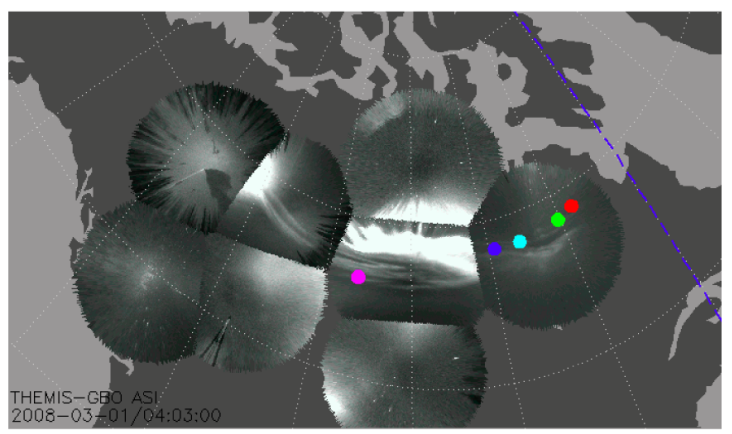

(B) at 03:58:12 UT

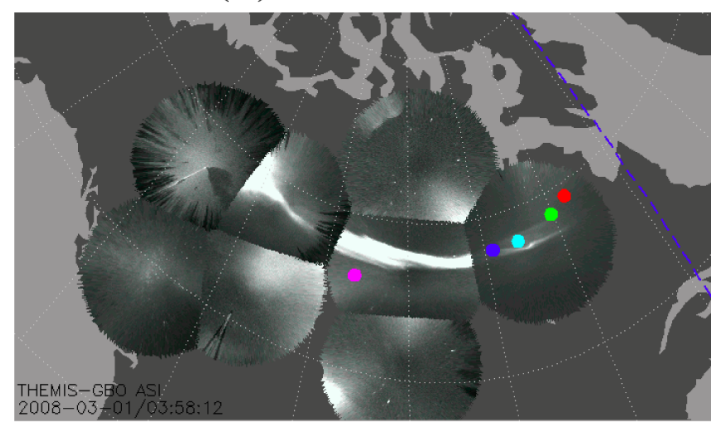

(D) at 04:08:00 UT

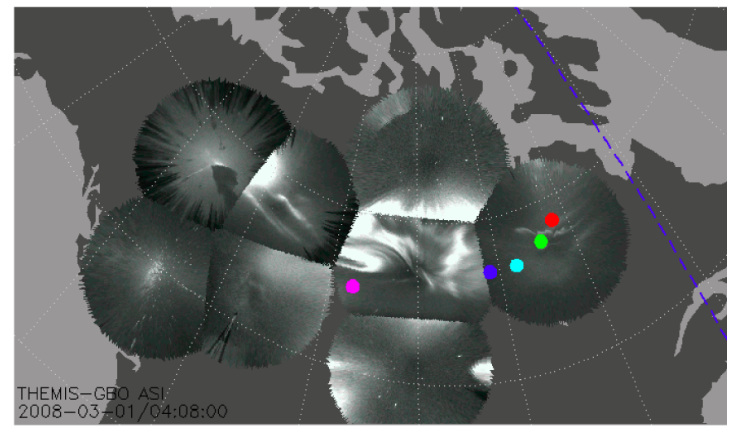

Fig. 4. (A)-(D) show mosaic ASI snapshots (of 3-s resolution) of the second event at four different times on 1 March 2008 . We focus on the substorm activities of the second event (E-2) because the first event has been classified as a pseudo-breakup. Footprints of the THEMIS satellites are mapped using the AM02 field model of Kubyshkina et al. (2009). The yellow circles are the all-sky fields of view at GILL and SNKQ, respectively. The footprint of TH-D (turquoise dot) is located almost on top of the onset arc at SNKQ at 03:58:12 UT.

TH-AL index in dotted curve is obtained from the THEMIS ground-based magnetometer data of 3-s resolution (Russell et al., 2008). The TH-AL index did not show any enhancement during the first event (E-1), as observed in the KyotoAL index.

The IT (image total) plots in Fig. 3 show the brightness of the onset arc. The solid IT curve shows the onset arc brightness at SNKQ. The dotted curve shows the brightness at GILL. Comparing the solid curve and the dotted curve, the onset arc at SNKQ is clearly brighter than at GILL during dipolarization onset. But the mosaic auroral photo shown in Fig. $4 \mathrm{~b}$ indicated otherwise. This is a problem of mosaic photos of unknown origin.

Brightening of onset arc based on the IT plot occurs when the IT curve starts to increase monotonically: brightening of the first onset arc (E-1) occurs at $\sim 03: 39: 48$ as marked by the first solid red line. Brightening of the second onset arc (E-2) occurs at $\sim 03: 57: 57$ when the IT curve start to increase monotonically as marked by the second solid red line in Fig. 3. Fluctuations in the IT curve prior to the brightening of the second onset arc (E-2) could be associated with background auroral activities. Accurate timing of brightening of the onset arc is made possible by the IT plot used in Angelopoulos et al. (2008), Runov et al. (2008), Mende et al. (2009).
The first event (E-1) is classified as a pseudo-breakup when the Kyoto-AL index decreases from $\sim-50 \mathrm{nT}$ to $\sim$ $-250 \mathrm{nT}$. Brightening of the first onset arc at $\sim 03: 39: 48$ was observed at both SNKQ and GILL to precede the dipolarization onset observed at TH-D at $\sim 03: 41: 00$ by $\sim 71 \pm 3 \mathrm{~s}$. The uncertainty of $\pm 3 \mathrm{~s}$ is associated to the ASI resolution.

The second event (E-2) is identified as a substorm when the Kyoto-AL index decreases from $\sim-250 \mathrm{nT}$ to $\sim-550 \mathrm{nT}$. Brightening of the second onset arc is complicated by the fluctuations in the IT curve prior to the onset. In this case, brightening of onset arc should be defined to occur when the IT curve starts to increase monotonically. Thus, brightening of the second onset arc is estimated to occur at $\sim 03: 57: 57$ UT, at both SNKQ and GILL, which precedes the second dipolarization onset at $\sim 03: 59: 17$ UT by $\sim 80 \pm 3 \mathrm{~s}$.

Dipolarization onset is based on the increase in the magnetic field tilt angle, TA, measured from the equatorial plane in the GSM coordinates defined in Sect. 2. The dipolarization onset is marked by the dashed red lines at TH-D and dotted red line at TH-E shown in Fig. 3. Dipolarization onset is estimated when the averaged TA starts to increase monotonically. The averaged TA is crudely estimated by eyeballing out the spiky fluctuations on the TA plots.

Figure 4 shows snapshots of the mosaic ASI's during the second event (E-2) from $\sim 03: 48$ to $\sim 04: 08$. These mosaic 
Table 1. Footprints of TH-D and TH-E during the second event (E-2) shown in Fig. 4.

\begin{tabular}{lcc}
\hline & TH-D GML (MLT) & TH-E GML (MLT) \\
\hline Fig. 4a at 03:48:00 & $67.82(22: 34)$ & $67.82(22: 14)$ \\
Fig. 4b at 03:58:12 & $66.98(22: 31)$ & $66.95(22: 12)$ \\
Fig. 4c at 04:03:00 & $67.24(22: 34)$ & $67.28(22: 15)$ \\
Fig. 4d at 04:08:00 & $65.85(22: 28)$ & $65.86(22: 09)$ \\
\hline
\end{tabular}

snapshots are useful for tracking the TH-spacecraft footprints relative to the onset arc location based on the AM02 field model (Kubyshkina et al., 2009). The TH-footprints are color coded: TH-A in pink, TH-B in red, TH-C in green, TH-D in turquoise, and TH-E in blue.

The GML-MLT coordinates of the TH-D and TH-E footprints are summarized in Table 1.

The yellow circles in Fig. 4a show the fields of view of all-sky cameras at GILL and SNKQ. The footprints of TH-D (turquoise dot) and TH-E (blue dot) are shown to be closely co-located with the onset arc as shown in Fig. 4b. Figure 4c and $\mathrm{d}$ are snapshots of the expanding auroral bulge during the substorm expansion phase.

The onset arc and the TH-D footprint (in turquoise dot) observed in Fig. 4b at 03:58:12 UT are located at $\sim 66.98 \mathrm{GML}$ and $\sim 22: 31$ MLT as shown in Table 1, which are in good agreement with the statistical results obtained by Frey et al. (2004) for the location of substorm onset arc at $\sim 66.4 \mathrm{GML}$ and $\sim 23: 00 \mathrm{MLT}$.

\subsection{The slow MHD waves dominate the disruption of cross-tail currents in the dipolarization region}

The fast MHD waves are characterized by the wave magnetic field and thermal pressure variations are in phase to result in increasing the wave speed to be greater than both the sound speed and Alfvén speed. On the other hand, the slow MHD waves are characterized by the wave magnetic field and thermal pressure variations are out of phase to result in reducing the wave speed to be less than both the Alfvén speed and the sound speed.

Appendix B derives the above well-known characteristics of the fast and slow MHD waves. The derivation is similar to the derivation given by Kantrowitz and Petschek (1966). We included the derivation here to make the physical meaning clearer in identifying the waves observed in the dipolarization region as the slow MHD waves.

Figure 5 shows that the slow MHD waves is the dominant waves observed in the dipolarization region using the bandpass filter for MHD waves [50-200 s]. The upper frequency $(1 / 50 \mathrm{~s}) \mathrm{Hz}$ of the band-pass filter is chosen to be about a factor 10 lower than the local ion cyclotron frequency as marked by the white curve in the wavelet spectrum in the bottom panels of Fig. 1a and b. Inputs to the filter are the
$B_{\mathrm{T}}=\left[\left(\boldsymbol{B}_{X}\right)^{2}+\left(\boldsymbol{B}_{Y}\right)^{2}+\left(\boldsymbol{B}_{Z}\right)^{2}\right]^{1 / 2}$ and $P_{\mathrm{T}}=\left(P_{i}+P_{e}\right)$ observed in the dipolarization region. Outputs of the filter are the MHD wave field $\delta \boldsymbol{B}_{\mathrm{T}}$ and pressure $\delta P_{\mathrm{T}}$.

Figure $5 \mathrm{a}$ and $\mathrm{b}$ show the results of TH-D data. The dashed line in Fig. 5a marks the dipolarization onset of the pseudo breakup event E-1; the dashed line in Fig. 5b marks the dipolarization onset of the full-scale substorm breakup event E2. The top panels of Fig. 5a and b of TH-D data show the MHD wave field $\delta \boldsymbol{B}_{\mathrm{T}}$ and pressure $\delta P_{\mathrm{T}}$. The middle panels show the product of $\delta \boldsymbol{B}_{\mathrm{T}} \delta P_{\mathrm{T}}$, which is mostly negative, i.e., the waves observed in the dipolarization region are predominantly the slow MHD waves according to the results of Appendix B.

Figure $5 \mathrm{c}$ and $\mathrm{d}$ show the results of filtered TH-E data, displayed in the same format as shown in Fig. 5a and b.

In summary, Fig. 5 shows that the dominant MHD waves in the dipolarization region are the slow MHD waves. Thus, the slow MHD waves can be inferred to dominate the disruption of the cross-tail current in the dipolarization region. The origin of the slow MHD waves in the dipolarization region will be discussed in Sect. 5 .

\section{Estimation of the Alfvén travel time on the TH-D field lines passing through the onset arc}

Knowing the TH-D field lines passing through the onset arc as shown in Fig. 4b enabled us to equate the Alfvén travel time estimated from the TH-D footprint (turquoise dot) to the TH-D spacecraft itself as a proxy for the Alfvén travel time from the substorm onset arc to the dipolarization onset region. Since the Cowling electrojet current enhances before each brightening of the onset arc, which predeces the dipolarization onset, we assume that the field-aligned currents is produced by the divergence of the Cowling electrojet and the Alfvén wave is launched to propagate the field-aligned currents. Thus, Alfvén waves are assumed to propagate from the ionosphere to the plasma sheet in our model to be discussed in Sect. 6.

Figure 6a shows the Alfvén travel path from the TH-D footprint in the ionosphere to the neutral sheet in the AM02 field model (Kubyshkina et al., 2009), which is an extension of the T96 field model as described in Sect. 2. The AM02 model is an improvement of the T96 model as demonstrated in Appendix A by comparing the results of AM02 model, T96 model and the THEMIS observations.

To estimate the Alfvén travel time, we need to estimate the Alfvén velocity defined by $C_{\mathrm{A}}=\boldsymbol{B}_{0} /\left(\mu_{0} \rho_{0}\right)^{1 / 2}$, where $\boldsymbol{B}_{0}$ is the magnetic field along the Alfvén travel path, $\mu_{0}$ is the permeability of free space, $\rho_{0}$ is the plasma mass density. The slight difference between the dashed red curve and the solid black curve indicating that the plasma sheet is more tail-like in the substorm event E-2 than in the pseudo breakup event E-1. 

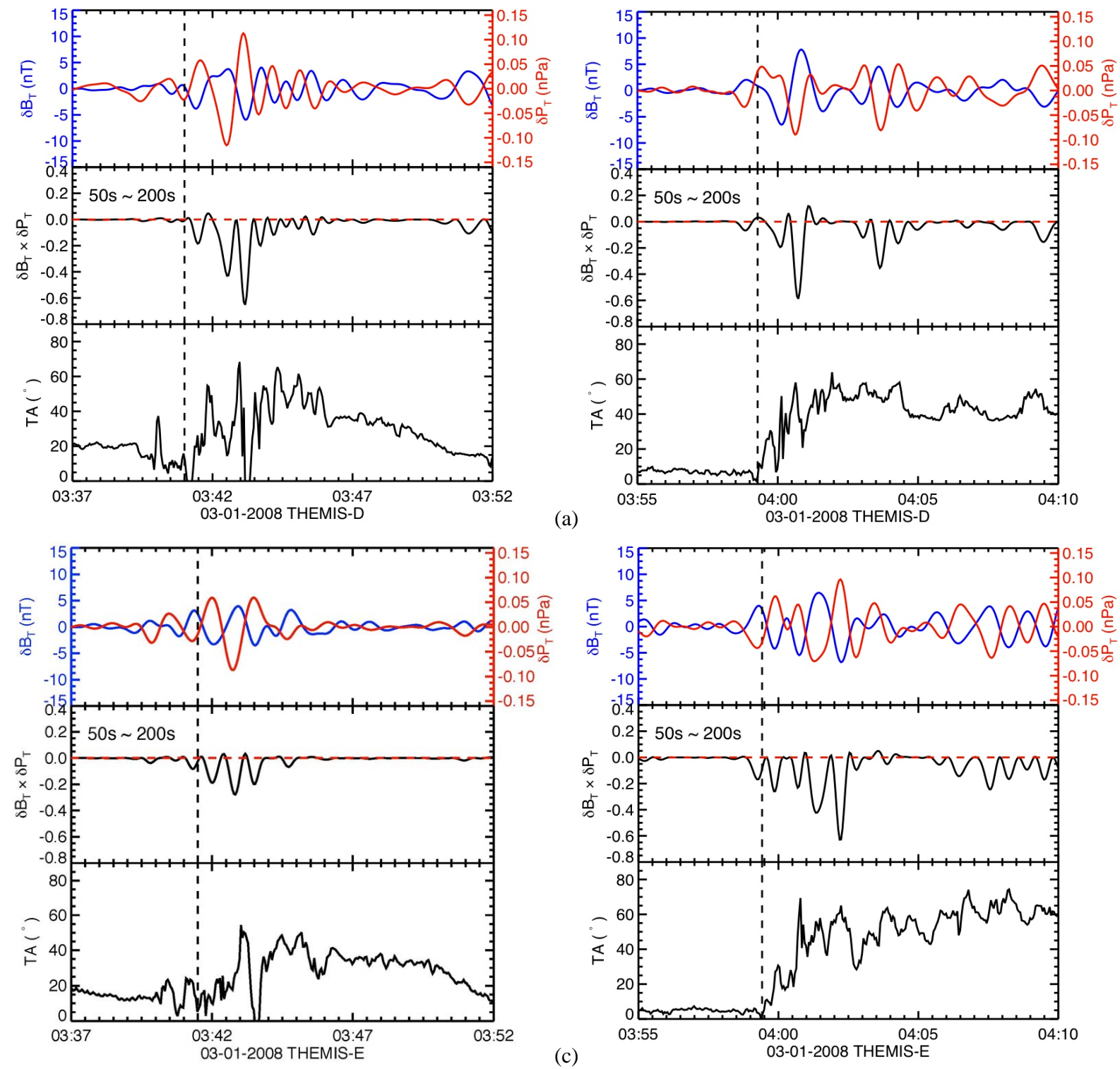

Fig. 5. Figure 5 show that the slow MHD waves dominate the disruption of cross-tail currents in the dipolarization region. (a) and (b) show MHD waves through the band-pass filter [50-200 s] on the TH-D data. The high frequency end of the band-pass filter, i.e., $1 / 50 \mathrm{~s} \sim 0.02 \mathrm{~Hz}$, is chosen to make sure that it is less than $\sim 0.1 \mathrm{~Hz}$ of the local ion cyclotron frequency shown by the white curve in the wavelet spectrum at the bottom panels of Fig. 1a and b. The top panels of (a) and (b) show the filtered MHD waves in $\delta \boldsymbol{B}_{\mathrm{T}}$ and $\delta P_{\mathrm{T}}$. The dashed vertical line in (a) marks the dipolarization onset of the pseudo breakup event in E-1; the dashed line in (b) marks the dipolarization onset of the full-scale substorm breakup event in E-2. The middle panels show the product of $\delta \boldsymbol{B}_{\mathrm{T}} \delta P_{\mathrm{T}}$, which is mostly negative, i.e., the waves observed in the dipolarization region are predominantly the slow MHD waves, according to the results of Appendix B. (c) and (d) show the results of filtered TH-E data, displayed in the same format as the TH-D data shown in (a) and (b).

In the absence of observed electron number density along field lines, we estimate the electron number density under the following assumptions:

Assumption-1: the magnetic flux is assumed conserved along a flux tube, i.e., $\boldsymbol{B} \times A=$ constant, where $\boldsymbol{B}$ is the magnetic field intensity and $A$ is the cross section of the flux tube.

Assumption-2: the electron flux is assumed conserved along a flux tube, i.e., $N V_{\|} \times A=$ constant. This assumption is valid as long as the frozen-in condition is valid. Elec- trons on a flux tube will stay on a flux tube under adiabatic variations.

Assumption-3: the flow speed along the flux tube is assumed constant, i.e., $V_{||}=$constant $\neq 0$. This is a weak assumption expected to hold in the absence of field-aligned potential drop. A posteriori support for Assumption-3 will be discussed after the Alfvén travel time is calculated based on Fig. 6c. 


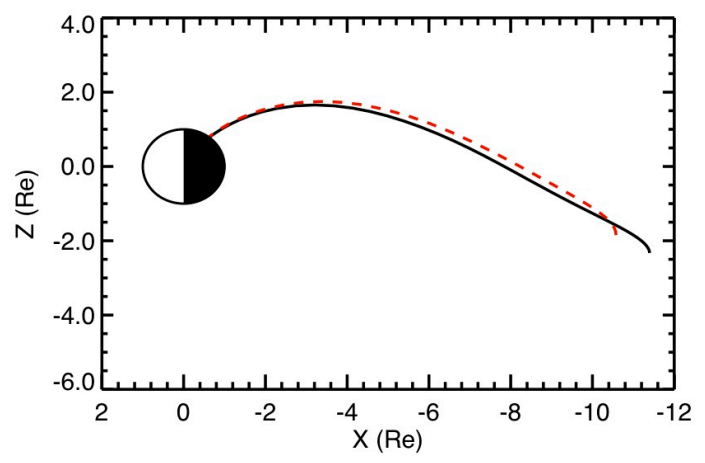

Fig. 6a. (a) shows the Alfvén travel path along the TH-D field lines from the footprint in the ionosphere, passing through the onset arc at 03:58:12 UT shown in the snapshot in Fig. 4b, to the dipolarization region based on the AM02 field model of Kubyshkina et al. (2009). The dashed red curve is for the E-1 event, the solid black curve is for the E-2 event.

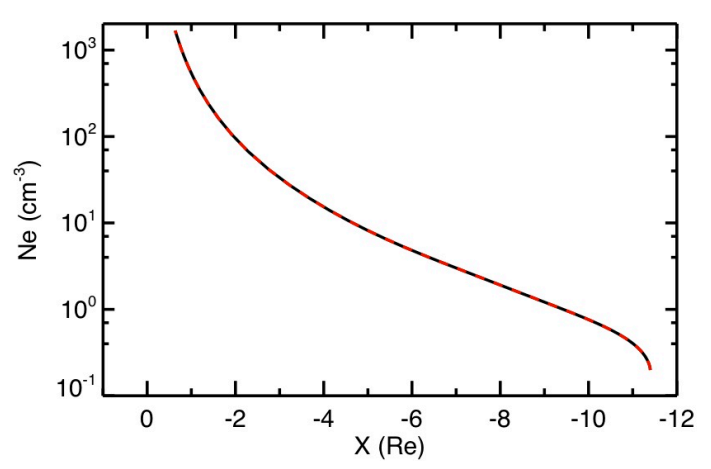

Fig. 6b. (b) shows the ion number density ( $\sim$ electron number density) along the Alfvén travel path estimated under the assumptions discussed in Sect. 5. The dashed red curve is for the E-1 event, the solid black curve is for the E-2 event.

Combining the three assumptions listed above, one obtains $N / B=$ constant. Thus, the Alfvén speed $C_{\mathrm{A}}$ along the Alfvén travel path should scale with $\boldsymbol{B}^{1 / 2}$.

Figure $6 \mathrm{~b}$ shows the electron number density along the Alfvén travel path calculated under the assumptions as discussed above. The electron number density from the T03 model is $\sim 0.198 \mathrm{~cm}^{-3}$ (Tsyganenko and Mukai, 2003). The averaged value measured at TH-D at $\sim 03: 58 \mathrm{UT}$ is $\sim 0.217 \mathrm{~cm}^{-3}$. For simplicity, we choose to use the electron number density in the neutral sheet at $\sim 0.2 \mathrm{~cm}^{-3}$ to start our calculation. The calculated electron (proton) number density near the ionosphere of the Alfvén travel path is $\sim 1680 \mathrm{~cm}^{-3}$ as shown in Fig. 6b, which is comparable to the number density of $\sim 1500 \mathrm{~cm}^{-3}$ at $\sim 1000-1200 \mathrm{~km}$ altitude found at http://ccmc.gsfc.nasa.gov/modelweb/models/iri.html.

Figure $6 \mathrm{c}$ shows the Alfvén speed calculated along the Alfvén travel path, based on the B-field in Fig. 6a and the proton ( electron) number density in Fig. 6 b.

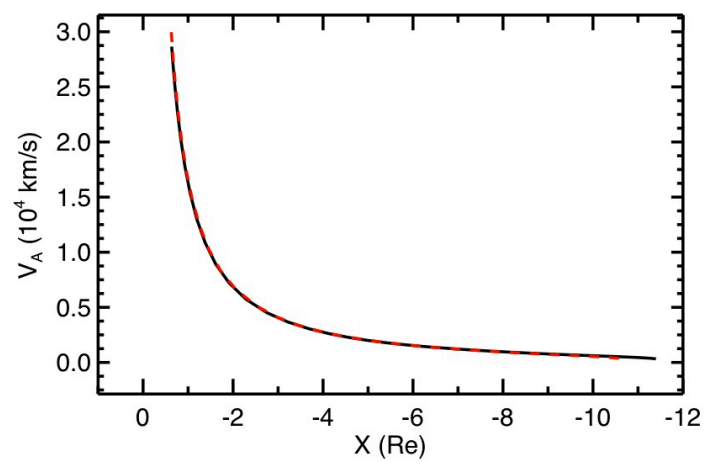

Fig. 6c. (c) shows the Alfvén speed estimated along the Alfvén travel path based on the B field shown in Fig. 6a, the number density in Fig. $6 \mathrm{~b}$ and the line integral algorithm discussed in Sect. 5. The dashed red curve is for the E-1 event, the soliar black curve is for the E-2 event.

Table 2. Comparison of Alfvén travel time and the time delay of the dipolarization onset from the brightening of the onset arc observed in E-1 and E-2.

Alfvén travel time from the
TH-D footprint to the neutral
sheet in the dipolarization re-
gion is estimated at:
$\bullet \sim 69.3 \mathrm{~s}$ in E-1;
$\bullet \sim 80.3 \mathrm{~s}$ in E-2.

Onset arc brightening at SNKQ preceded the dipolarization onset at TH-D is estimated at:

- $71 \pm 3$ s in E-1;

$\bullet \sim 80 \pm 3$ s in E-2.

The Alfvén travel time $T_{\mathrm{A}}$ is calculated using the lineintegral algorithm, written as $T_{\mathrm{A}}=\Sigma_{i}\left(\Delta R_{i} / C_{\mathrm{A} i}\right)$ where $\Sigma_{i}$ is the summation over the index $i=1,2, . ., \Delta R_{i}$ is the distance element along the Alfvén travel path between $\left(X_{i}, Y_{i}, Z_{i}\right)$ and $\left(X_{i+1}, Y_{i+1}, Z_{i+1}\right)$, and $C_{\mathrm{A} i}$ is the Alfvén speed at $\left(X_{i}, Y_{i}, Z_{i}\right)$ along the travel path. The Alfvén travel time obtained from the above line-integral algorithm along field lines from the TH-D footprint to the neutral sheet $\left(\boldsymbol{B}_{X}\right.$ changes sign) is estimated at $\sim 80.3 \mathrm{~s}$.

Since the estimated Alfvén travel time comes mostly from $X<-3 R_{\mathrm{E}}$ in the near-Earth plasma sheet as can be visualized in Fig. 6c, the Assuption-3 weakened by the presence of field-aligned potential drop in the ionosphere would not have serious effect. A much cruder estimate of the Alfvén travel time has been made in Angelopoulos et al. (2008).

Comparison of Alfvén travel time and the time delay of the dipolarization onset from the brightening of the onset arc observedin E-1 and E-2 are listed in Table 2. 


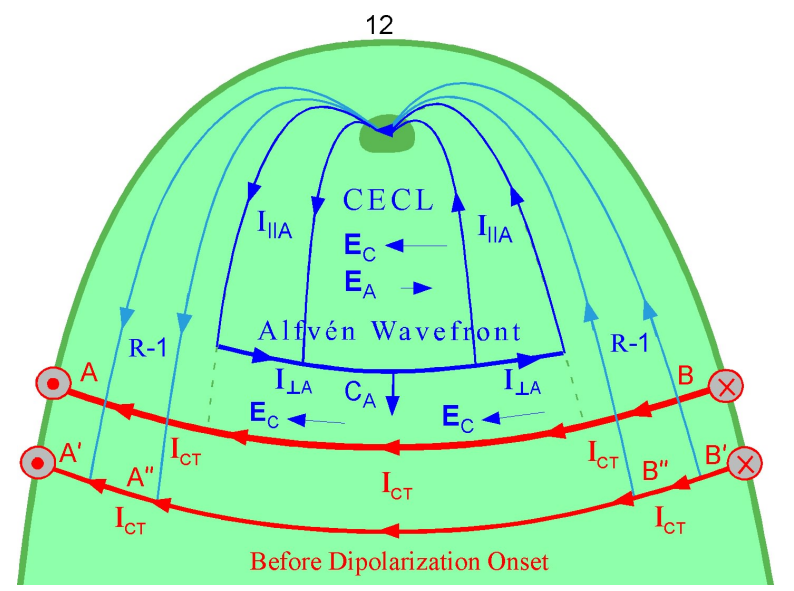

Fig. 7a. (a) depicts the CECL model before dipolarization onset. Dipolarization onset in the CECL model is initiated by the CECL interacting with the plasma sheet to disrupt the cross-tail current in the dipolarization region. The CECL is a closed Cowling electrojet current loop formed by the divergence and convergence, respectively, on the dusk-side and dawn-side of the Cowling electrojet channel. The Alfvén wavefront leads the propagation of the CECL towards the plasma sheet. Inside the CECL, the E-field is $\boldsymbol{E}^{\prime}=\boldsymbol{E}_{\mathrm{C}}+\boldsymbol{E}_{\mathrm{A}}$. The energy flow to power the CECL model before the dipolarization onset is discussed in Sect. 5.1.

\section{The CECL model for the dipolarization onset during southward IMF}

We propose that the observed dipolarization onset can be modeled by the Cowling electrojet current loop (CECL) interacting with the near-Earth plasma sheet to disrupt the cross-tail current in the dipolarization region. Observational bases for the proposed CECL model have been discussed in Sects. 3 and 4 . Theoretical bases for the proposed CECL model have been discussed in part by Kan (2007), which is further developed in this section.

Figure $7 \mathrm{a}$ and $\mathrm{b}$ are snapshots of the CECL model before and after the dipolarization onset in the CECL substorm model. The CECL is produced by the divergence (convergence) on the dusk-side (dawn-side) of the Cowling electrojet current channel leading to the formation of the 3-D CECL current loop. Since currents must flow in closed current loops at all times, the field-aligned currents in the CECL are closed in the Alfvén wavefront as shown in Fig. 6a. The Alfvén wavefront leads the propagation of the CECL toward the near-Earth plasma sheet.

Brightening of the onset arc begins when the upward fieldaligned current density in the CECL exceeds $\sim 1 \mu \mathrm{A} \mathrm{m}^{-2}$ (Anderson and Vondrak, 1975; Iijima and Potemra, 1978), as the Alfvén wavefront propagates towards the plasma sheet as shown in Fig. 6a. The dipolarization onset occurs when the Alfvén wavefront of CECL incident on the near-Earth plasma sheet, leading to disrupting the cross-tail currents in the dipolarization region as shown in Fig. 6b.

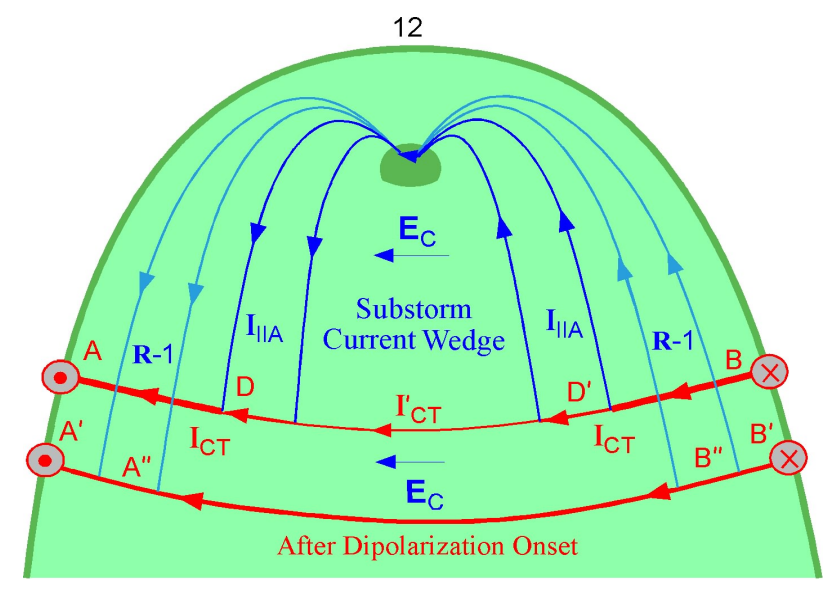

Fig. 7b. (b) depicts the CECL model after the dipolarization onset. Energy flow to power the CECL model after the dipolarization onset is discussed in Sect. 5.1.

\subsection{Energy flow in the CECL model}

The energy flows, prior to the dipolarization onset, from the SW-M (solar wind-magnetosphere) dynamo to the cross-tail currents in the plasma sheet. The Region-1 field-aligned currents (R-1) are connected to the cross-tail current between $\mathrm{A}^{\prime}-\mathrm{A}^{\prime \prime}$ and between $\mathrm{B}^{\prime}-\mathrm{B}^{\prime \prime}$ to power the CECL as shown in Fig. 6a. Current closure in the CECL model satisfies the Walén solution of nonlinear Alfvén wave in incompressible uniform plasma obtained in 1944 found in Alfvén and Falthammar (1963). The closure current in the CECL can be derived from the Walén solution of nonlinear Alfvén waves as shown in Eq. (4) of Kan and Sun (1996). The earthward convection in the plasma sheet is powered by the cross-tail currents while the equatorward convection in the ionosphere is powered by the R-1 field-aligned currents connected to the cross-tail currents which are connected to the SW-M dynamo where $\boldsymbol{E}_{\mathrm{D}} \times \boldsymbol{I}_{\mathrm{D}}<0$ along the magnetotail (not shown).

Figure $6 \mathrm{~b}$ shows the energy flow in the CECL model after the dipolarization onset. Dipolarization onset occurs when the Alfvén wavefront incident on the near-Earth plasma sheet to disrupt the cross-tail current in the dipolarization region, i.e., to reduce the cross-tail current between points D-D'. After the dipolarization onset, the CECL is connected to the cross-tail current to form the substorm (Pashin et al., 1982; Lopez and Lui, 1990; Belehaki et al., 1998). The SW-M dynamo provides the energy consumed in the substorm current (SCW).

\subsection{Dipolarization onset driven by CECL interacting with the plasma sheet}

Dipolarization onset in the CECL model is caused by the interaction of the Alfvén wavefront with the near-Earth plasma sheet. The incident Alfvén wavefront excites the slow MHD 
waves to disrupt the cross-tail current in the dipolarization region as discussed in Sect. 3.3.

Alfvén wavefront depicted in Fig. 6a is based on the Walén solution of nonlinear Alfvén waves. The current flowing in the Alfvén wavefront is anti-parallel to the cross-tail current in the plasma sheet. The interaction between the Alfvén wavefront should exciting MHD waves to disrupt the crosstail current in the dipolarizing region. We showed in Fig. 5 that the slow MHD waves are the dominant waves responsible for disrupting the cross-tail current in the dipolarization region.

Southwood and Saunders (1985) discussed coupling of MHD Slow wave and Alfvén wave due to curvature of field lines in the plasma sheet. Ohtani et al. (1989) discussed coupling of Alfvén and Slow waves in non-uniform finite-beta plasma to explain Pc5 pulsations. Saito et al. (2008) discussed MHD waves observed in the near-Earth plasma sheet prior to dipolarization. Du et al. (2011) discussed mode conversion between Alfvén and slow MHD waves in the plasma sheet around $\sim 11 R_{\mathrm{E}}$ under extremely quiet condition.

\section{Discussions of unresolved issues}

\subsection{Why some onset arcs terminate in the short-lived pseudo breakups?}

Answer to this question should await the results of a statistical study of onset arcs. For the time being, we can only compare the characteristic features observed in the case study of a pseudo breakup event in E-1 and a full-scale breakup event in E-2, as shown in Fig. 1a and b:

1. The $-\mathrm{AL}$ index $\leq \sim 200 \mathrm{nT}$ for pseudo breakup in E-1, while $-\mathrm{AL} \leq \sim 500 \mathrm{nT}$ for the full-scale breakup in E-2.

2. The plasma sheet thinning in E-1 is weak with TA $\sim 20^{\circ}$ compare with the intense thinning in E-2 with TA $<\sim 4^{\circ}$ as shown in Fig. 1a and b.

3. Dipolarization onset of the pseudo breakup event in E1 is preceded by fluctuations in the TA plot. On the other hand, dipolarization onset of the substorm event in E-2 is free from such fluctuations. These fluctuations could be a characteristic feature of the pseudo breakup event, to differentiate from the dipolarization onset of the substorm event.

Of the three conditions for the pseudo breakup, we believe condition (1) could be the most critical condition for the pseudo breakup because it controls the energy available to drive the breakup of the onset arc. The pseudo breakup appears to run out of energy as characterized by premature termination of the breakup arc without significant poleward expansion (Koskinen et al., 1993), and the premature termination of the dipolarization as shown in Fig. 1a and b.

\subsection{What role does reconnection play in the near-Earth Plasma Sheet?}

Careful inspections of $V_{X}$ in Fig. 1a and b show that the large-scale earthward convection enhances no more than a few tens of $\mathrm{km} \mathrm{s}^{-1}$ superposed by a few small-scale shortlived BBF of $\sim 200$ to $\sim 400 \mathrm{~km} \mathrm{~s}^{-1}$ during the period from $\sim 03: 40$ to $\sim 04: 12$ UT. The question is whether these flows are driven by the enhanced dayside reconnection following southward turning of the IMF or by reconnection produced by the growth phase thinning around $\sim-20 \pm 5 R_{\mathrm{E}}$ (Hones Jr. et al., 1984).

Near-Earth $X$-line has been inferred by observations in the plasma sheet around $\sim 20 \pm 5 R_{\mathrm{E}}$, for example by Nagai et al. (1998), Baumjohann et al. (1999), Slavin et al. (2002), Miyashita et al. (2004), Nagai et al. (2005), Petrukovich et al. (1998), Runov et al. (2008), Gabrielse et al. (2009), Miyashita et al. (2009). The locations of the observed X-line are comparable to the location of the observed growth phase thinning (Hones Jr. et al., 1984). How these X-lines are related to the substorm growth phase or expansion phase is still an open question.

\subsection{Necessary and sufficient conditions for the dipolarization onset in the CECL model}

Necessary conditions for dipolarization onset:

- brightening of onset arc (Akasofu, 1964)

- oval conductance enhanced (Hardy et al., 1987)

- Cowling electrojet intensified by southward E-field component in the midnight sector (Mozer, 1971)

Sufficient condition for dipolarization onset:

- when the CECL (Cowling electrojet current loop) incident on the near-Earth plasma sheet to disrupt the crosstail current in the dipolarization region

\section{CECL model of substorm consistent with a case study of THEMIS observation on 1 March 2008}

THEMIS observations of the substorm event (E-2) on 1 March 2008 are summarized below:

I. Brightening of the first onset arc preceded the first dipolarization onset at TH-D by $\sim 82 \pm 3 \mathrm{~s}$. The breakup arcs faded within a few minutes without substantial pole-ward expansion as shown in Fig. 2a. The dipolarization in the first event lasted for less than $\sim 10 \mathrm{~min}$ as seen in Fig. 3. We classified the first event as a pseudobreakup. 

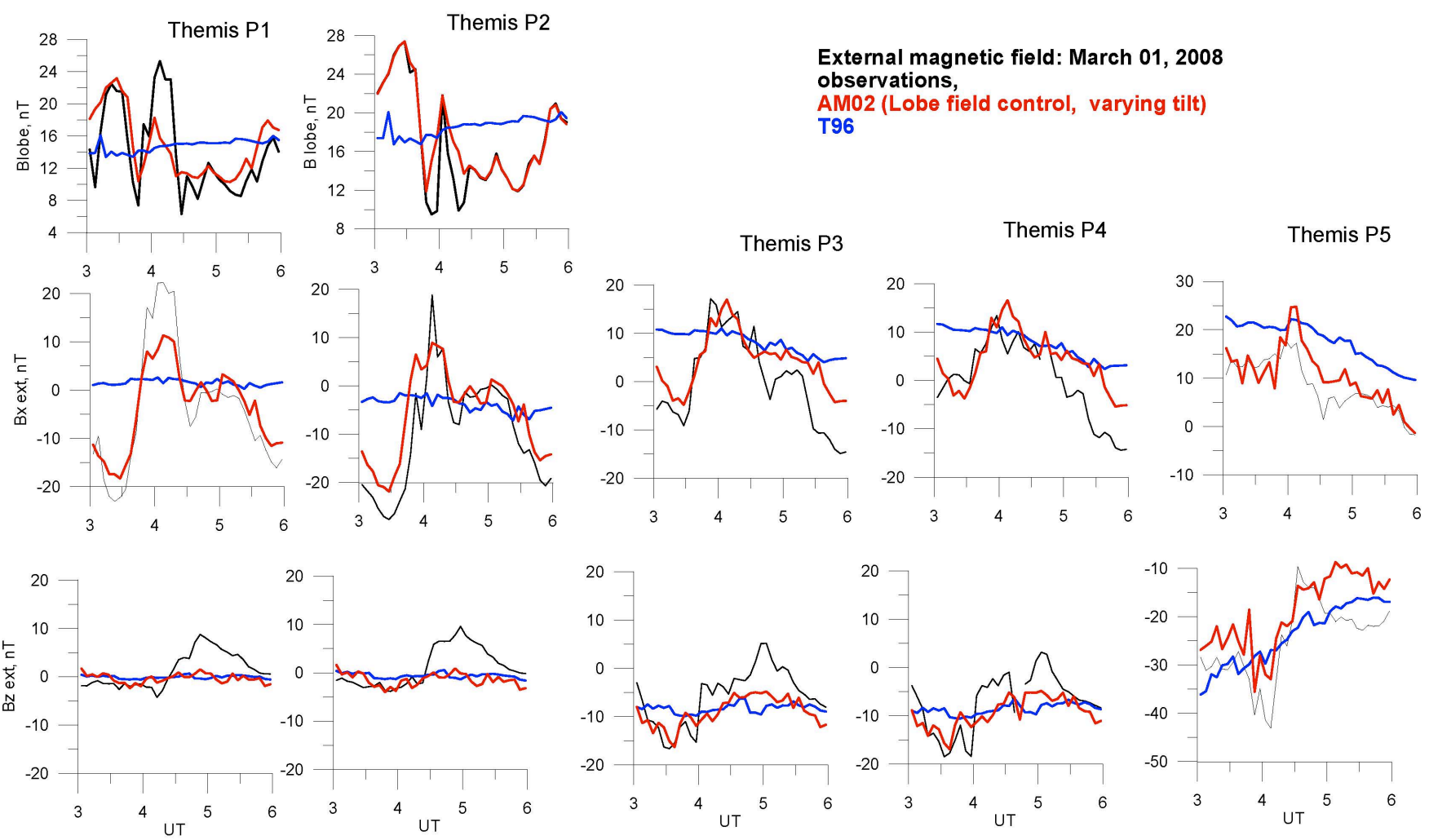

Fig. A1 Red curves show the magnetic field of AM02, blue curvesshow the results of T96, black curves are the observed magnetic fieldat the five $\mathrm{TH}$ probes (P1 to P5).

II. Brightening of the second onset arc preceded the second dipolarization onset at TH-D by $80 \pm 3 \mathrm{~s}$ as estimated in Fig. 3. The breakup arcs lasted at least $\sim 10 \mathrm{~min}$ as shown in Fig. 2b. The second dipolarization was sustained for more than $\sim 60 \mathrm{~min}$, even after the IMF turned northward, as shown in Fig. 1a and b. We identified the second event as a substorm.

III. The Slow MHD waves dominate the cross-tail current disruption process in the dipolarization region.

IV. The Alfvén travel time from the footprint of TH-D, passing through the substorm onset arc, to the TH-D spacecraft itself in the dipolarization region is estimated at $\sim 80.3 \mathrm{~s}$ in the second event as shown in Sect. 5. The Alfvén travel time matched well with the time delay of $\sim 80 \pm 3 \mathrm{~s}$ from the brightening of the onset arc to the dipolarization onset in the second event estimated in Fig. 3.

The CECL substorm model proposed in the present paper is consistent with the case study of the substorm event (E2) on 1 March 2008. A comprehensive statistical study is required to verify the commonality of the results summarized above.

\section{Appendix A}

\section{Comparison of AM02 results and $\mathrm{T} 96$ results with TH observations}

Here we demonstrate that the AM02 model better reproduces the magnetic field observed by all five THEMIS probes than the standard T96 model. Figure A1 demonstrate that the magnetic fields observations (in black) on 1 March 2008 of the five THEMIS probes, in comparison with the AM02 (in red), and T96 (in blue). It is clearly discernable that the AM02 reproduces the observed magnetic field much better than T96.

\section{Appendix B}

\section{Deriving the characteristics of the fast and slow MHD waves}

The following derivation is similar to that given by Kantrowitz and Petscheck (1966). 
To linearize the MHD equations, let's define the perturbations quantities by

$$
\begin{aligned}
& \rho=\rho_{0}+\delta \rho \\
& p=p_{0}+\delta p \\
& \boldsymbol{B}=\boldsymbol{B}_{0}+\delta \boldsymbol{B} \\
& \boldsymbol{V}=\delta \boldsymbol{V}
\end{aligned}
$$

where subscript " 0 " denotes the background equilibrium state and $\delta \rho, \delta p, \delta \boldsymbol{B}$, and $\delta \boldsymbol{V}$ denote the perturbed mass density, pressure, magnetic field, and velocity, respectively.

Taking $\partial / \partial t$ of the linearized continuity equation, one obtains

$$
\frac{\partial^{2} \delta \rho}{\partial t^{2}}=-\rho_{0} \frac{\partial}{\partial t}(\nabla \times \delta \boldsymbol{V})
$$

Taking divergence of the linearized momentum equation and making use of the Ampere's law, yields

$$
\begin{aligned}
\rho_{0} & \frac{\partial}{\partial t}(\nabla \times \delta \boldsymbol{V})=-\nabla^{2} \delta p+\nabla \cdot\left(\frac{\nabla \times \delta \boldsymbol{B}}{\mu_{0}} \times \boldsymbol{B}_{0}\right) \\
& =-\nabla^{2} \delta p+\nabla \cdot\left(\frac{\left(\boldsymbol{B}_{0} \cdot \nabla\right) \delta \boldsymbol{B}}{\mu_{0}}-\frac{\nabla\left(\delta \boldsymbol{B} \cdot \boldsymbol{B}_{0}\right)}{\mu_{0}}\right) \\
& =-\nabla^{2} \delta p+\left(\frac{\left(\boldsymbol{B}_{0} \cdot \nabla\right)(\nabla \cdot \delta \boldsymbol{B})}{\mu_{0}}-\frac{\nabla^{2}\left(\delta \boldsymbol{B} \cdot \boldsymbol{B}_{0}\right)}{\mu_{0}}\right)
\end{aligned}
$$

Since $\nabla \cdot \boldsymbol{B}=0$ it follows that $\nabla \cdot \delta \boldsymbol{B}=0$. The divergence of the linearized momentum equation becomes

$\rho_{0} \frac{\partial}{\partial t}(\nabla \cdot \delta \boldsymbol{V})=-\nabla^{2}\left(\delta p+\frac{\delta \boldsymbol{B} \cdot \boldsymbol{B}_{0}}{\mu_{0}}\right)$

Substituting Eq. (B1) into Eq. (B2) to eliminate $\delta \boldsymbol{V}$, leads to

$$
\frac{\partial^{2} \delta \rho}{\partial t^{2}}=\nabla^{2}\left(\delta p+\frac{\delta \boldsymbol{B} \cdot \boldsymbol{B}_{0}}{\mu_{0}}\right)
$$

From the definition $\delta \boldsymbol{B}=\boldsymbol{B}-\boldsymbol{B}_{0}$, and following the standard first-order approximation, one obtains

$$
B_{0} \delta B=\boldsymbol{B}_{0} \cdot \delta \boldsymbol{B}
$$

Equation (B4) states that if $\delta \boldsymbol{B}$ is perpendicular to $\boldsymbol{B}_{0}$, then $\delta B=0$, which is the case for Alfvén waves. On the other hand, if $\delta \boldsymbol{B}$ is parallel to $\boldsymbol{B}_{0}$, then $\delta B \neq 0$, which is the case for the Fast or Slow waves.

Substituting Eq. (B4) into Eq. (B3) yields

$$
\frac{\partial^{2} \delta \rho}{\partial t^{2}}=\nabla^{2}\left(\delta p+\frac{B_{0} \delta B}{\mu_{0}}\right)
$$

The adiabatic equation of state can be written as

$$
\frac{\delta p}{p_{0}}=\frac{\gamma \delta \rho}{\rho_{0}} \text { or } \delta p=C_{\mathrm{S} 0}^{2} \delta \rho
$$

where $C_{\mathrm{S} 0}^{2}=\gamma p_{0} / \rho_{0}$ is sound speed squared.
Substituting Eq. (B6) into Eq. (B5) and transferring the resulting equation into the $(\omega, \mathbf{k})$ domain, one obtains

$$
\left(\frac{\omega^{2}}{k^{2}}-C_{\mathrm{S} 0}^{2}\right) \delta \rho=\frac{B_{0} \delta B}{\mu_{0}}
$$

Upon substituting the second part of Eq. (B6) into Eq. (B7), one obtains

$$
\left(\frac{\omega^{2}}{k^{2} C_{\mathrm{S} 0}^{2}}-1\right) \delta p=\frac{B_{0} \delta B}{\mu_{0}}
$$

We conclude from Eq. (B8)

1. For $\omega^{2} / k^{2}>C_{\mathrm{S} 0}^{2}$, which is the case for the MHD Fast waves, Eq. (B8) leads to $\delta p \delta \boldsymbol{B}>0$, i.e., $\delta p$ and $\delta B$ are in-phase.

2. For $\omega^{2} / k^{2}<C_{\mathrm{S} 0}^{2}$, which is the case for the MHD Slow waves, Eq. (B8) leads to $\delta p \delta \boldsymbol{B}<0$, i.e., $\delta p$ and $\delta \boldsymbol{B}$ are out-of-phase.

Acknowledgements. This research is supported in part by the National Natural Science Foundation of China (No. 40831060) and the Specialized Research Fund for State Key Laboratories in China. One of us (J. R. Kan) is supported in part by the HAARP project under ONR grant N00014-08-1-0439 to the University of Alaska Fairbanks. The THEMIS ASI network of GBO stations are supported by the Canadian Space Agency. The authors gratefully acknowledge the use of data made available by the Image Team, the MACCS Team, and the Kyoto World Data Center.

Topical Editor I. Daglis thanks two anonymous referees for their help in evaluating this paper.

\section{References}

Akasofu, S.-I.: The development of the auroral substorm, Planet. Space Sci., 12, 273-282, 1964.

Alfvén, H. and Falthammar, C. G.: Cosmical Electrodynamics, Fundamental Principles, Clarendon, Oxford, 1963.

Anderson, H. R. and Vondrak, R. R.: Observations of Birkeland currents at auroral latitudes, Rev. Geophys. Space Phys., 13, 243 262, 1975.

Angelopoulos, V., Baumjohann, W., Kennel, C. F., Coroniti, F. V., Kivelson, M. G., Pellat, R., Walker, R. J., Lühr, H., and Paschmann, G.: Bursty bulk flows in the inner central plasma sheet, J. Geophys. Res., 97, 4027-4039, 1992.

Angelopoulos, V., McFadden, J. P., Larson, D., Carlson, C. W., Mende, S. B., Frey, H., Phan, T., Sibeck, D. G., Glassmeier, K. H., Auster, U., Donovan, E., Mann, I. R., Rae, I. J., Russell, C. T., Runov, A., Zhou, X. Z., and Kepko, L.: Tail reconnection triggering substorm onset, Science, 321, 931-935, 2008.

Baker, D. N., Pulkkinen, T. I., Angelopoulos, V., Baumjohann, W., and McPherron, R. L.: Neutral line model of substorms: Past results and present view, J. Geophys. Res., 101, 12975-13010, 1996.

Baumjohann, W., Paschmann, G., and Lühr, H: Characteristics of high-speed ion flows in the plasma sheet, J. Geophys. Res., 95, 3801-3809, 1990. 
Baumjohann, Hesse, M., Kokubun, S., Mukai, T., Nagai, T., and Petrukovich, A. A.: Substorm dipolarization and recovery, J. Geophys. Res., 104, 24995-25000, 1999.

Belehaki, A., Tsagouri, I., and Mavromichalaki, H.: Study of the longitudinal expansion velocity of the substorm current wedge, Ann. Geophys., 16, 1423-1433, doi:10.1007/s00585-998-14239, 1998.

Bostrom, R.: Ionosphere-magnetosphere coupling, in: Magnetospheric Physics, edited by: McCormac, B. M., D. Reidel, Hingham, MA, p. 45, 1974.

Coroniti, F. V. and Kennel, C. F.: Can the ionosphere regulate magnetospheric convection?, J. Geophys. Res., 78, 2837-2851, 1973.

Du, J., Zhang, T. L., Nakamura, R., Wang, C., Baumjohann, W., Du, A. M., Volwerk, M., Glassmeier, K.-H., and McFadden, J. P.: Mode conversion between Alfvén and slow waves observed in the magnetotail by THEMIS, Geophys. Res. Letts, 38, L07101, doi:10.1029/2011GL046989, 2011.

Dubyagin, S., Sergeev, V., Apatenkov, S., Angelopoulos, V., Nakamura, R., McFadden, J., Larson, D., and Bonnell, J.: Pressure and entropy changes in the flow-braking region during magnetic field dipolarization, J. Geophys. Res., 115, A10225, doi:10.1029/2010JA015625, 2010.

Frey, H. U., Mende, S. B., Angelopoulos, V., and Donovan, E. F.: Substorm onset observations by IMAGE-FUV, J. Geophys. Res., 109, A10304, doi:10.1029/2004JA010607, 2004.

Gabrielse, C., Angelopoulos, V., Runov, A., Frey, H., McFadden, J. P., Larson, D. E., Glassmeier, K., Mende, S., Russell, C. T., Apatenkov, S., Murphy, K. R., Rae, I. J., and Raeder, J.: Timing and localization of near-Earth tail and ionospheric signatures during a substorm onset, J. Geophys. Res., 114, A00C13, doi:10.1029/2008JA013583, 2009.

Goertz, C. K. and Boswell, R. W.: Magnetosphereionospherec oupling, J. Geophys. Res., 84, 7239-7246, doi:10.1029/JA084iA12p07239, 1979.

Hardy, D. A., Gussenhoven, M. S., Raistrick, R., and McNeil, W. J.: Statistical and functional representations of the pattern of auroral energy flux, number flux, and conductivity, J. Geophys. Res., 92, 12275-12294, 1987.

Heppner, J. P. and Maynard, N. C.: Empirical high-latitude electric field models, J. Geophys. Res., 92, 4467-4489, 1987.

Hones Jr., E. W., Pytte, T., and West Jr., H. I.: Associations of geomagnetic activity with plasma sheet thinning and expansion: A statistical study, J. Geophys. Res., 89, 5471-5478, 1984.

Iijima, T. and Potemra, T. A.: Large-scale characteristics of fieldaligned currents associated with substorms, J. Geophys. Res., 83, 599-615, doi:10.1029/JA083iA02p00599, 1978.

Iijima, T., Potemra, T. A., and Zanetti, L. J.: Large-Scale characteristics of magnetospheric equatorial currents, J. Geophys. Res., 95, 991-999, doi:10.1029/JA095iA02p00991, 1990.

Kamide, Y. and Kokubun, S.: Two-component auroral electrojet: Importance for substorm studies, J. Geophys. Res., 101, 1302713046, 1996.

Kan, J. R.: On the formation of near-Earth $\mathrm{X}$ line at substorm expansion onset, J. Geophys. Res., 112, A01207, doi:10.1029/2006JA012011, 2007.

Kan, J. R. and Sun, W.: Substorm expansion phase caused by an intense localized convection imposed on the ionosphere, J. Geophys. Res., 101, 27271-27281, doi:10.1029/96JA02426, 1996.

Kantrowitz, A., and Petschek, H. E.: MHD characteristics and shock waves, in: Plasma Physics in Theory and Application, edited by: Kunkel, W. B., McGraw-Hill Inc., New York, p. 148, 1966.

Kaufmann, R. L.: Substorm currents: Growth phase and onset, J. Geophys. Res., 92, 7471-7486, doi:10.1029/JA092iA07p07471, 1987.

Koskinen, H. E. J., Lopez, R. E., Pellinen, R. J., Pulkkinen, T. I., Baker, D. N., and Bösinger, T.: Pseudobreakup and substorm growth phase in the ionosphere and magnetosphere, J. Geophys. Res., 98, 5801-5813, doi:10.1029/92JA02482, 1993.

Kubyshkina, M., Sergeev, V., Tsyganenko, N., Angelopoulos, V., Runov, A., Singer, H., Glassmeier, K. H., Auster, H. U., and Baumjohann, W.: Toward adapted time-dependent magnetospheric models: A simple approach based on tuning the standard model, J. Geophys. Res., 114, A00C21, doi:10.1029/2008JA013547, 2009.

Lopez, R. E. and Lui, A. T. Y.: A multisatellite case study of the expansion of a substorm current wedge in the near-Earth magnetotail, J. Geophys. Res., 95, 8009-8017, 1990.

Lui, A. T. Y., Yoon, P. H., Mok, C., and Ryu, C.-M.: Inverse cascade feature of current disruption, J. Geophys. Res., 113, A00C06, doi:10.1029/2008JA013521, 2008.

Maltsev, Yu. P., Leontyev, S. V., and Lyatsky, W. B.: Pi 2 pulsations as a result of evolution of an Alfv6n impulse originating in the ionosphere during a brightening of the aurora, Planet. Space Sci., 22, 1519-1533, doi:10.1016/0032-0633(74)90017-8, 1974.

Mende, S., Harris, S. E., Frey, H. U., Angelopoulos, V., Russell, C. T., Donovan, E., Jackel, B., Greffen, M., and Peticolas, L. M.: The THEMIS array of ground-based observatories for the study of auroral substorms, Space Sci. Rev., 141, 357-387, doi:10.1007/s11214-008-9380-x, 2008.

Mende, S., Angelopoulos, V., Frey, H. U., Donovan, E., Jackel, B., Glassmeier, K.-H., McFadden, J. P., Larson, D., and Carlson, C. W.: Timing and location of substorm onsets from THEMIS satellite and ground based observations, Ann. Geophys., 27, 28132830, doi:10.5194/angeo-27-2813-2009, 2009.

Miyashita, Y., Kamide, Y., Machida, S., Liou, K., Mukai, T., Saito, Y., Ieda, A., Meng, C.-I., and Parks, G. K.: Difference in magnetotail variations between intense and weak substorms, J. Geophys. Res., 109, A11205, doi:10.1029/2004JA010588, 2004.

Miyashita, Y., Machida, S., Kamide, Y., Nagata, D., Liou, K., Fujimoto, M., Ieda, A., Saito, M. H., Russell, C. T., Christon, S. P., Nose, M., Frey, H. U., Shinohara, I., Mukai, T., Saito, Y., and Hayakawa, H.: A state-of-the-art picture of substormassociated evolution of the near-Earth magnetotail obtained from superposed epoch analysis, J. Geophys. Res., 114, A01211, doi:10.1029/2008JA013225, 2009.

Mozer, F. S.: Origin and effects of electric fields during isolated magnetospheric substorms, J. Geophys. Res., 76, 7595-7608, doi:10.1029/JA076i031p07595, 1971.

Nagai, T., Fujimoto, M., Saito, Y., Machida, S., Terasawa, T., Nakamura, R., Yamamoto, T., Mukai, T., Nishida, A., and Kokubun, S.: Structure and dynamics of magnetic reconnection for substorm onsets with Geotailobservations, J. Geophys. Res., 103, 4419-4440, doi:10.1029/97JA02190, 1998.

Nagai, T., Fujimoto, M., Nakamura, R., Baumjohann, W., Ieda, A., Shinohara, I., Machida, S., Saito, Y., and Mukai, T.: Solar wind control of the radial distance of the magnetic reconnection site in the magnetotail, J. Geophys. Res., 110, A09208, 
doi:10.1029/2005JA011207, 2005.

Ohtani, S., Miura, A., and Tamao, T.: Coupling between Alfvén and Slow magnetosonic waves in an inhomogeneous finite- $\beta$ plasma, I. Coupled equations and physical mechanism, Planet. Space Sci., 37, 567-511, 1989.

Ohtani, S., Takahashi, K., Zanetti, L. J., Potemra, T. A., McEntire, R. W., and Iijima, T.: Initial signatures of magnetic field and energetic particle fluxes at tail reconfiguration: Explosive growth phase, J. Geophys. Res., 97, 19311-19324, doi:10.1029/92JA01832, 1992.

Pashin, A. B., Raspopov, O. M.,Iakhnin, A. G., Glassmeier, K. H., Baumjohann, W., Opgenoorth, H. J., and Pellinen, R. J.: Pi 2 magnetic pulsations, auroral break-ups, and the substorm current wedge: A case study, J. Geophys.-Z. Geophys., 51, 223-233, 1982.

Petrukovich, A. A., Sergeev, V. A., Zelenyi, L. M., Mukai, T., Yamamoto, T., Kokubun, S., Shiokawa, K., Deehr, C. S., Budnick, E. Y., Buchner, J., Fedorov, A. O., Grigorieva, V. P., Hughes, T. J., Pissarenko, N. F., Romanov, S. A., and Sandahl, I.: Two spacecraft observations of a reconnection pulse during an auroral breakup, J. Geophys. Res., 103, 47-59, 1998.

Runov, A., Angelopoulos, V., Zhou, X. Z., Voronkov, I. O., Kubyshkina, M. V., Nakamura, R., Carlson, C. W., Frey, H. U., McFadden, J., Larson, D., Mende, S. B., Glassmeier, K. H., Auster, U., and Singer, H. J.: Multipoint in situ and groundbased observations during auroral intensifications, J. Geophys. Res., 113, A00C07, doi:10.1029/2008JA013493, 2008.

Russell, C. T., Chi, P. J., Dearborn, D. J., Ge, Y. S., Kuo-Tiong, B., Means, J. D., Pierce, D. R., Rowe, K. M., and Snare, R. C.: THEMIS ground-based magnetometers, Space Sci. Rev., 141, 389-412, doi:10.1007/s11214-008-9337-0, 2008.

Saito, M. H., Miyashita, Y., Fujimoto, M., Shinohara, I., Saito, Y., and Mukai, T.: Modes and characteristics of low-frequency MHD waves in the near-Earth magnetotail prior to dipolarization: Fitting method, J. Geophys. Res., 113, A06201, doi:10.1029/2007JA012778, 2008.
Shiokawa, K., Baumjohann, W., and Haerendel, G.: Braking of highspeed flows in the near-Earth tail, Geophys. Res. Lett., 24, 1179-1182, 1997.

Senior, C. and Blanc, M.: On the control of magnetospheric convection by the spatial distribution of ionospheric conductivities, J. Geophys. Res., 89, 261-284, 1984.

Slavin, J. A., Fairfield, D. H., Lepping, R. P., Hesse, M., Ieda, A., Tanskanen, E., Ostgaard, N., Mukai, T., Nagai, T., Singer, H. J., and Sutcliffe, P. R.: Simultaneous observations of earthward flow bursts and plasmoid ejection during magnetospheric substorms, J. Geophys. Res., 107, 1106, doi:10.1029/2000JA003501, 2002.

Southwood, D. J. and Saunders, M. A.: Curvature coupling of slow and Alfvén MHD waves in a magnetotail field configuration, Planet. Space Sci., 33, 127-134, doi:10.1016/00320633(85)90149-7, 1985.

Torrence, C. and Compo, G. P.: A Practical Guide to Wavelet Analysis, B. Am. Meteorol. Soc., 79, 61-78, doi:10.1175/15200477(1998)079<0061:APGTWA>2.0.CO;2, 1998.

Tsyganenko, N. A.: Modeling the Earth's magnetospheric magnetic field confined within a realistic magnetopause, J. Geophys. Res., 100, 5599-5612, 1995.

Tsyganenko, N. A. and Mukai, T.: Tail plasma sheet models derived from Geotail particle data, J. Geophys. Res., 108, 1136, doi:10.1029/2002JA009707, 2003.

Vörös, Z., Runov, A., Leubner, M. P., Baumjohann, W., and Volwerk, M.: Is current disruption associated with an inverse cascade?, Nonlin. Processes Geophys., 17, 287-292, doi:10.5194/npg-17-287-2010, 2010.

Wolf, R. A.: Effects of ionospheric conductivity on convective flow of plasma in the magnetosphere, J. Geophys. Res., 75, 46774698, doi:10.1029/JA075i025p04677, 1970.

Xing, X., Lyons, L. R., Angelopoulos, V., Larson, D., Carlson, C., Runov, A., and Auster, U.: Plasma sheet pressure evolution related to substorms, J. Geophys. Res., 115, A01212, doi:10.1029/2009JA014315, 2010. 